\title{
Evaluation of health-related quality of life in patients with Kashin-Beck disease using a new questionnaire $\mathbb{A}$ cross-sectional study
}

\author{
Zhankui Jin \\ Shaanxi Provincial People's Hospital \\ Zhengming Sun \\ Shaanxi Provincial People's Hospital \\ Xueyuan Wu \\ Shaanxi Provincial People's Hospital \\ Ming Chen \\ Shaanxi Provincial People's Hospital \\ Bo Yang \\ Shaanxi Provincial People's Hospital \\ Xianghui Dong \\ Shaanxi Provincial People's Hospital \\ Shizhang Liu \\ Shaanxi Provincial People's Hospital \\ Yanhai Chang \\ Shaanxi Provincial People's Hospital \\ Cuixiang $X \mathbf{u}$ \\ Shaanxi Provincial People's Hospital \\ Zhi Yi ( $\square$ yizhisyy@163.com) \\ Shaanxi Provincial People's Hospital \\ Ming Ling \\ Shaanxi Provincial People's Hospital
}

\section{Research Article}

Keywords: Kashin-Beck disease, Endemic, Quality of life, Cross-sectional study, Questionnaire

Posted Date: January 28th, 2022

DOI: https://doi.org/10.21203/rs.3.rs-1111411/v2

License: (c) (1) This work is licensed under a Creative Commons Attribution 4.0 International License. Read Full License 


\section{Abstract}

Objective: Kashin-Beck disease (KBD) is an endemic deformable bone and joint disease, which seriously affects the quality of life (QOL) of patients. We tried to conduct a cross-sectional study of the QOL of KBD patients by a new KBD quality of life (KBDQOL) questionnaire.

Methods: 252 KBD patients came from Northwest China, and 260 healthy people living in the same area as KBD patients served as the control group. KBDQOL questionnaire was used to evaluate the QOL of all objects.

Results: The average score of physical functions, activity limitations, support of society, mental health and general health of KBD patients was significantly lower than that in control group. There was no statistical difference in economics between KBD patients and control group. The univariate analysis showed that age, height, weight status, education level and grade of KBD had a statistically significant effect on KBDQOL score. The results of multivariate analysis showed that grade of KBD was the influencing factor of physical function score; sex, age, height, grade of KBD and duration of symptoms were the influencing factors of activity restriction score; grade of KBD was the influencing factor of economic score, age and grade of KBD were influencing factors of general health.

Conclusions: The QOL of patients with KBD was significantly lower than that of healthy people living in the same place. The KBDQOL questionnaire may be a promising tool for assessing the QOL of KBD patients.

\section{Introduction}

Although Kashin-Beck Disease (KBD) was reported more than 150 years ago, this disease continues to affect the health of some people in Asia[1]. KBD mainly affects the development of bone and cartilage of the limbs in children and adolescents from 5 to 15 years old[2-3]. The primary lesions of KBD mainly invade the epiphyseal cartilage, epiphyseal plate cartilage and articular cartilage during the development of osteochondrosis of the limbs in children, and are characterized by multiple, symmetrical degeneration and coagulative necrosis of deep cartilage cells and their secondary osteoarthropathy[4].

The most common clinical symptoms of KBD include joint pain, joint thickening, joint deformity and limited mobility, severe short stature, short finger (toe) deformity, and muscle atrophy[5]. KBD's knee joint deformity is significantly more serious than common osteoarthritis (OA), which seriously affects the patient's life and work. With the development of the disease, the deformity of the knee joint becomes more and more serious, and even the knee joint function is lost, which seriously affects the quality of life (QOL) of KBD patients[6]. Therefore, it is necessary to evaluate the quality of life and health status of KBD patients.

There are already several methods for assessing the health status of patients with OA in different aspects. The WOMAC and Lequesne indexes are special indicators of $\mathrm{OA}$, which mainly focus on the effects of physical functions, physical symptoms and diseases, but they cannot reflect other aspects of QOL, such as psychology, social interactions, etc[7-8]. SF-36 and the European five-dimensional questionnaire (EuroQol five dimensions questionnaire, EQ-5D) have been widely used in the study of OA patients, but they are not very sensitive to measuring the results of specific disease interventions[9]. Most KBD patients cannot understand meaning of certain items in SF-36, because these patients come from remote mountainous areas, with low education and low comprehension skills. Therefore, Guo Xiong's research team has developed a new, simple and practical KBD Quality of Life (KBDQOL) questionnaire[9]. The questionnaire can capture the characteristics of KBD patients, can meet the psychometric characteristics required by clinical trials and observational research, and is easy to understand. In this study, we tried to use the KBDQOL questionnaire to assess the QOL and health status of KBD patients, and to understand the QOL gap between KBD patients and local healthy people.

\section{Methods}

\section{Patients}

The study subjects were divided into KBD patients and the control group. All patients were diagnosed as KBD. The control group consisted of healthy people living in the same area as the KBD patients, and no diabetes, osteoarthritis, rheumatoid arthritis, tumors, stroke with limb inflexibility, severe cardiopulmonary disease, and other diseases that affect their lives quality.

Inclusion criteria: patients with severe knee pain are diagnosed with end-stage KBD and are between 18 and 70 years old. Healthy people in the same area as KBD patients, between the ages of 18 and 70 years old.

The exclusion criteria: post-traumatic arthritis or deformity, persistent infection of the knee joint or other parts of the body.

\section{KBD clinical diagnosis}

KBD was diagnosed as follows according to clinical criteria (GB16003-1995): A residence history of more than 6 months in a KBD endemic area, with symptoms such as multiple, symmetrical finger joint swelling or brachydactyly, etc[10]. These diseases should be excluded, such as $\mathrm{OA}$, rheumatoid arthritis, gout, rickets, cretinism, familial short stature, primary dwarfism, metaphyseal development disorders, achondroplasia, pseudoepiphyseal dysplasia, multiple epiphyseal dysplasia Caused by short stature, mental retardation and sexual development disorders. The diagnostic classification criteria were defined as follows: grade I, there are multiple symmetrical finger joints and extremities joint swelling of other joints, limited flexion and extension activities, pain, and mild muscle atrophy; grade II, on the basis of grade I, the symptoms and signs develop more severely and develop into brachydactyly; grade III, based on grade II, the symptoms and signs become more severe, and the limbs are short and deformed[11].

\section{Collection of baseline data}


Baseline of gender, age, height, weight, body mass index, education level, KBD classification, course of disease, drinking, smoking, hypertension, diabetes, tumor, stroke, mental illness, genetic disease of KBD patients and the control group data were collected.

The education level was divided into five standard levels:(1) no education completed, (2) first level (primary school), (3) secondary level (first phase), (4) secondary level (second phase), and (5) third level, which included university and other forms of higher education[12].

\section{KBDQOL evaluation}

KBDQOL questionnaire is a KBD-specific QOL evaluation scale (Supplementary Table 1[6]), and an important tool for evaluating disease-specific QOL in KBD patients. KBDQOL data for each object was collected. The KBDQOL questionnaire has 28 items and 6 areas. Its brief contents are as follows: physical function (7 items), activity limitation (5 items), support of society (4 items), economics (3 items), mental health (5 items) and general health (four items). Each item has 5 options, and all items are scored from 1 to 5 . The survey time is the past 4 weeks[9].

We calculate the average score for each domain as follows: average score for physical function = (Q1.1 + Q1.2 + Q1.3 + Q2.1 + Q2.2 + Q2.3 + Q3.4) / 7, average score for activity limitation = (Q1.4 + Q1. $5+\mathrm{Q} 1.6+\mathrm{Q} 1.7+\mathrm{Q} 1.8) / 5$, average support of society score $=(\mathrm{Q} 4.2+\mathrm{Q} 5.5+\mathrm{Q} 5.6+\mathrm{Q} 5.8) / 4$, average economics score $=(\mathrm{Q} 6.1+\mathrm{Q} 6.2+\mathrm{Q} 6.3) / 3$, the average mental health score $=(\mathrm{Q} 4.1+\mathrm{Q} 4.4+\mathrm{Q} 4.5+\mathrm{Q} 4.6+\mathrm{Q} 5.4) / 5$, the total average general health score $=$ $(\mathrm{Q} 7.1+\mathrm{Q} 7.2+\mathrm{Q7.3}+\mathrm{Q7.4}) / 4$. The average score of each domain before and after surgery, 5 is the best average score[13]. A high score implies a high quality of life[9].

Investigator training: two investigators independently performed KBDQOL assessment of KBD patients to reduce observation bias. All investigators should receive 3 hours of training. The purpose of the training is to understand the purpose and significance of the survey, the structure and definition of the questionnaire, the description and explanation of related knowledge, unify the meaning and filling method of the indicators, and clarify the survey workflow and precautions. The environment during the investigation should be a quiet environment, with no other people interfering with the investigation[13].

\section{Statistical analysis}

Use SPSS (windows version 22.0) for statistical analysis. Demographic characteristics and clinical characteristics were expressed as mean \pm standard deviation (measurement data) or absolute value (count data). The data of each group containing continuous variables were tested for normal distribution and homogeneity of variance. Two independent-sample t-tests were used for the comparison of continuous variables with normal distribution and homogeneity of variance, and single-factor analysis of variance was used for multi-group comparisons. Two groups of continuous variables without normal distribution and homogeneity of variance were compared using the Mann-Whitney $U$ test with non-parametric test, and Kruskal-Wallis test with non-parametric test was used for multi-group comparison. The comparison of count data uses chi-square test. Because the dependent variables of physical function, activity limitation, support of society, economics, mental health and general health data of KBD patients were all non-normally distributed. The dependent variable was converted into categorical variable data, and the ordinal multi-category logistic regression analysis was used for multi-factor analysis. The dependent variable physical function, activity limitation, support of society, economics, mental health and general health continuity variable data are converted into categorical variables, defined as: $<1.00=0,1.00 \sim 1.99=1,2.00 \sim 2.99=2,3.00 \sim 3.99=3,4.00 \sim 5.00=4$. The independent variables gender, smoking, drinking, hypertension and diabetes were designed as dummy variables in SPSS software. $P$ value less than 0.05 is statistically significant.

\section{Results}

\section{Demographic baseline data}

There were $252 \mathrm{KBD}$ patients, 99 males and 153 females, with an average age of $59.94 \pm 8.22$ years old, and an average course of $27.23 \pm 15.50$ years. There were 260 people in the control group, 118 males and 142 females, with an average age of $59.10 \pm 8.60$ years old. There was no statistical difference between KBD patients and the control group in demographic and clinical characteristics. The detailed data are shown in Table 1. The physical characteristics and joint $\mathrm{X}$-ray features of KBD patients were shown in Figure 1.

\section{The KBDQOL scores of KBD and control group}

KBD patients on the KBDQOL questionnaire had an average physical function score of $2.43 \pm 0.75$, an average activity limitation score of $3.60 \pm 0.89$, an average support of society score of $3.23 \pm 0.85$, an average mental health score of $3.23 \pm 1.12$, and an average general health score of $2.49 \pm 0.60$, which was significantly lower than the average score of the control group $(4.89 \pm 0.14,4.89 \pm 0.20,4.33 \pm 0.50,4.33 \pm 0.38$ and $3.73 \pm 0.31)$. The average score of KBD patients in economics was $2.49 \pm 0.92$, which was not statistically different from the control group $(2.58 \pm 1.05, P=0.511)$, but on the average score of Q6.1 question, KBD patients were significantly lower than the control group (respectively, $2.40 \pm 1.19,2.65 \pm 1.20, P=0.011$ ). The score comparison between $\mathrm{KBD}$ patients and the control group on the 28 sub-items of the KBDQOL scale is shown in Table 2 and Figure 2.

\section{The monofactor analysis of the KBDQOL scores in patients with KBD}

We performed a monofactor analysis of the KBDQOL scores for KBD patients to understand whether gender, age, height, weight status, education, grade of KBD, disease course, smoking, drinking, blood pressure and blood sugar affect the KBDQOL scale scores for KBD patients. We found that physical function, activity limitation, mental health and general health were statistically different in different age groups. Physical function, activity limitation and general health were statistically different in different height groups. Activity limitation and general health had statistical differences between different weight status groups. Physical function, activity limitation and support of society had statistical differences in different education groups. Physical function, activity limitation, economics and general health have statistical differences in different grade of KBD groups. In summary, monofactor analysis showed that age, height, weight 
status, education and grade of KBD had statistically significant effects on the KBDQOL scores of KBD patients, while factors such as sex, disease duration, smoking, drinking, blood pressure, and blood glucose did not have a substantial effect on the KBDQOL scores of KBD patients (Table 3).

\section{Multivariate analysis of factors affecting the scores of KBDQOL scale in KBD patients}

We used ordinal multi-category logistic regression analysis to control confounding factors. KBD patients' physical function, activity limitation, support of society, economics, mental health, and general health average scores were converted into categorical variables. Ordinal multi-category logistic regression analysis was performed on the influencing factors such as gender, age, height, weight status, education, grade of KBD, disease course, smoking, drinking, blood pressure and blood sugar.

The results showed that grade of KBD was the influencing factor of physical function score; gender, age, height, grade of KBD and duration of symptoms were the influencing factors of activity restriction score; grade of KBD was the influencing factor of economic score; and age and grade of KBD were factors affecting the general health score (Table 4).

\section{Discussion}

In this study, we conducted a large cross-sectional study to evaluate the QOL of patients with KBD by the KBDQOL questionnaire, a new KBD-specific QOL tool. The results emphasized that the QOL of KBD patients were significantly lower than that of healthy people in the same region. Our data demonstrated that the $\mathrm{KBDQOL}$ questionnaire is a promising tool for assessing the QOL of KBD patients. To our knowledge, this study was the first evaluation to examine the QOL for KBD patients by a new KBD-specific quality of life instrument KBDQOL.

There are already many scales to evaluate different aspects of the health status of OA patients, such as WOMAC, Lequesne index, SF-36 and EQ-5D. Recently, the EQ-5D was used to measure the health-related quality of life (HRQOL) of KBD patients for the first time. Research results showed that KBD has a serious impact on patients' HRQOL, especially in pain, discomfort, mobility, anxiety, and depression[14-15]. Compared with non-KBD participants and the general population in Beijing, KBD patients had a higher percentage of VAS scores and EQ-5D. The EQ-5D was used because there was no specific questionnaire that can be used to measure HRQOL related to KBD. KBD has some special characteristics, for example, its initial symptoms in early childhood are more serious than $\mathrm{OA}$, so it is necessary to develop a dedicated HRQOL scale for KBD.

Most KBD patients are farmers living in rural areas of Shaanxi Province and they have no primary education. KBDQOL is a low-educated KBD population survey that can be easily used in rural areas, and most of the questions are direct statements from KBD patients[9]. Some studies[16-18] reported the symptoms and signs of KBD, but none of the studies linked the clinical manifestations of KBD to patients' disability, restriction of daily activities, the impact of disease on income, and the impact of disease on mood. We found that KBD patients do often have restricted activities, financial difficulties, and negative emotions. Physical disability leads to reduced income, affects family life, and further affects family relationships. Therefore, the final KBDQOL questionnaire includes items such as burdens, emotions, and financial difficulties related to daily activities.

Comparing KBDQOL with SF-36, some aspects are unique to KBDQOL (for example, social support, economics, etc.). Among the 12 physical function and activity limitation items of KBDQOL, only $66 \%$ and $50 \%$ respectively are part of the WOMAC and Lequesne indexes, respectively[18]. During the personal interview, more than $40 \%$ of the patients put forward two new contents as follow: Q2.2, in the past 30 days, "How many days do you need to take painkillers?" and Q3.4, "Do you sleep well? How many days are good?".

Because KBDQOL is a disease-specific QOL scale for KBD, it solves the problem of no scale model that can be used for comparison so far, and applies the World Health Organization QOL concept and framework to define the relevant items of KBDQOL[9]. EQ-5D is often used to measure the QOL of chronic musculoskeletal diseases and has good reliability[19]. In addition to social support and economics, the interrelationships of all aspects of KBDQOL are well related to the corresponding aspects of EQ-5D[14].

KBDQOL is suitable for KBD patients over 18 years old who have a clear awareness and ability to communicate[13]. Since more than $90 \%$ of KBD patients live in remote rural areas in China and have a low level of education[20], the content of the KBDQOL questionnaire is simple and easy to understand. It is suitable for face-to-face surveys for people educated in junior high school and below. Investigators should fill out the form and use a uniform standard description. For those who have a high school degree or above and can fill in themselves, they can fill out the form themselves.

During this investigation, there was a detail that cannot be ignored. When the investigator asked KBD patients "Do you feel that you are a burden or burden at home? (Q4.4)" and "Do you feel that you are not well-grown (short stature, deformed joints) and are unwilling to go out? (Q4. 6)", in these two questions, all patients answered: "always", and some patients showed very sad expressions when they answered the questions. When asked "Your physical condition is compared with people of the same age and sex (Q7.2)", all patients answered: "Much worse". All patients felt that they had brought a heavy burden to the whole family and had a stronger sense of inferiority compared with their peers. They were reluctant to go out due to their short stature, ugly appearance or ugly walking posture. This reflected that KBD patients were under tremendous psychological pressure and their QOL is poor. It also demonstrated that KBDQOL can accurately capture the psychological characteristics of KBD patients.

Our study has potential limitations. Although the inductive method was used to explore the views of KBD patients on QOL, KBDQOL still lacks the views of other stakeholders, such as patients' caregivers and family members. Therefore, further research is needed to test the clinical reactivity and applicability of KBDQOL in different cultural backgrounds.

\section{Conclusions}


This study evaluated the QOL and health status of KBD patients by a new KBDQOL questionnaire. We conducted 28 questions in 6 domains including physical function, activity limitation, social support, economics, mental health and general health for each object. The results highlighted that the average score of physical functions, activity limitations, support of society, mental health and general health of KBD patients was significantly lower than the average score of the control group, except for economics. Our data exhibited that the KBDQOL questionnaire may be a promising tool for assessing the QOL of KBD patients.

\section{Declarations}

\section{Ethics approval and consent to participate}

This study was approved by the Ethics Committee of Shaanxi Provincial People's Hospital (approval number: 20190806), and the subjects were informed and signed an informed consent form in strict accordance with the Declaration of Helsinki. A written informed consent was obtained from all subjects

before enrollment.

\section{Consent for publication}

All authors approved the submitted final manuscript and agreed to be responsible for all aspects of the work.

\section{Availability of data and materials}

The authors declare that the raw data are available.

\section{Competing interests}

The authors declare that they have no conflicts of interest.

\section{Funding}

This study was supported by Talent Support Program of Shaanxi Provincial People's Hospital (2021BJ-04), Shaanxi Provincial People's Hospital Technology Development Incubation Fund (2020YXM-02), Key Scientific Research Project of Shaanxi Provincial Department of Education (21JS039), and Shaanxi Province Key R\&D Program (2020SF-303, 2018ZDXM-SF-054).

\section{Authors' contributions}

Zhan-Kui Jin, Zhi Yi and Ming Ling made substantial contributions to the conception or design of the work, acquisition, analysis, and interpretation of data for the work; Zhan-Kui Jin, Zhi Yi, Xiang-Hui Dong, Ming Chen, Xue-Yuan Wu, Zheng-Ming Sun, Bo Yang, Yan-Hai Chang, Cui-Xiang Xu and Shi-Zhang Liu drafted the work and revised it critically for important intellectual content; all authors approved the final version to be published; all authors agreed to be accountable for all aspects of the work in ensuring that questions related to the accuracy or integrity of any part of the work are appropriately investigated and resolved.

\section{Acknowledgements}

We thank Pengzhen Lei, Xin Tian and Xianghui Huang for their English editorial assistance.

\section{Author details}

${ }^{1}$ Department of Orthopaedics, Shaanxi Provincial People's Hospital, Xi'an 710068, China

${ }^{2}$ Shaanxi Provincial Key Laboratory of Infection and Immune Diseases, Shaanxi Provincial People's Hospital, Xi'an 710068, China

\section{Abbreviations}

KBD: Kashin-Beck Disease; OA: osteoarthritis; QOL: quality of life; EQ-5D: EuroQol five dimensions questionnaire; KBDQOL: KBD Quality of Life; HRQOL: health-related quality of life.

\section{References}

1. Hinsenkamp M. Kashin-Beck disease. Int Orthop. 2001; 25: 133. https://doi.org/10.1007/s002640000177.

2. Cao J, Li S, Shi Z, Yue Y, Sun J, Chen J, et al. Articular cartilage metabolism in patients with Kashin-Beck Disease: an endemic osteoarthropathy in China. Osteoarthritis Cartilage. 2008; 16: 680-8. https://doi.org/10.1016/j.joca.2007.09.002.

3. Stone R. Diseases. A medical mystery in middle China. Science. 2009; 324: 1378-81. https://doi.org/10.1126/science.324_1378.

4. Wang X, Ning Y, Zhang P, Li C, Zhou R, Guo X. Hair multi-bioelement profile of Kashin-Beck disease in the endemic regions of China. J Trace Elem Med Biol. 2019; 54: 79-97. https://doi.org/10.1016/j.jtemb.2019.04.002.

5. Xiong G. Diagnostic, clinical and radiological characteristics of Kashin-Beck disease in Shaanxi Province, PR China. Int Orthop. 2001; 25: 147-50. 
6. Jin ZK, Yang Y, Xu CX, Yang B, Lammi MJ, Chang YH, et al. Outcomes of total knee arthroplasty in the adult Kashin-Beck disease with severe osteoarthritis. Int Orthop. 2019; 43: 323-31. https://doi.org/10.1007/s00264-018-4029-1.

7. Angst F, Ewert T, Lehmann S, Aeschlimann A, Stucki G. The factor subdimensions of the Western Ontario and McMaster Universities Osteoarthritis Index (WOMAC) help to specify hip and knee osteoarthritis. a prospective evaluation and validation study. J Rheumatol. 2005; 32: 1324-30.

8. Dawson J, Linsell L, Doll H, Zondervan K, Rose P, Carr A, et al. Assessment of the Lequesne index of severity for osteoarthritis of the hip in an elderly population. Osteoarthritis Cartilage. 2005; 13: 854-60. https://doi.org/10.1016/j.joca.2005.05.006.

9. Fang H, Guo X, Farooq U, Xia C, Dong R. Development and validation of a quality of life instrument for Kashin-Beck disease: an endemic osteoarthritis in China. Osteoarthritis Cartilage. 2012; 20: 630-7. https://doi.org/10.1016/j.joca.2012.03.004.

10. Disease CODC. Diagnostic Criteria of Kaschh-Beck Disease. Chinese Journal of Endemiology. 1994: 309.

11. Liu N. Interpretation of Diagnostic Criteria for Kashin - Beck Disease. China Health Standard Managemen. 2010; 1: 56-8.

12. Cavelaars AE, Kunst AE, Geurts JJ, Crialesi R, Grotvedt L, Helmert U, et al. Differences in self reported morbidity by educational level: a comparison of 11 western European countries. J Epidemiol Community Health. 1998; 52: 219-27. https://doi.org/10.1136/jech.52.4.219.

13. Fang H, Guo X, Xi C, Wang D. Introduction and use guide of Kashin-Beck disease patients' quality of life scale. Chinese Journal of Endemiology. 2014; 33 : 446-9.

14. Fang H, Farooq U, Wang D, Yu F, Younus MI, Guo X. Reliability and validity of the EQ-5D-3L for Kashin-Beck disease in China. Springerplus. 2016 ; 5: 1924. https://doi.org/10.1186/s40064-016-3613-3.

15. Farooq U, Guo X, Chuang LH, Fang H, Zhuang G, Xia C. Measuring health-related quality of life in Kashin-Beck disease using EQ-5D. Qual Life Res. 2011; 20: 425-9. https://doi.org/10.1007/s11136-010-9820-4.

16. Dang J, Li H, Niu K, Xu Z, Lin J, He Z. Kashin-Beck disease diagnosis based on deep learning from hand X-ray images. Comput Methods Programs Biomed. 2021; 200: 105919. https://doi.org/10.1016/j.cmpb.2020.105919.

17. Zou K, Hu J, Zhou Q, Su J, Dong B, Zhang W. The effectiveness of treatments for Kashin-Beck disease: a systematic review and network meta-analysis. Clin Rheumatol. 2019; 38: 3595-607. https://doi.org/10.1007/s10067-019-04704-0.

18. Yang L, Wang D, Li X, Yuan H, Fang H, Guo X. Comparison of the responsiveness of the WOMAC and the 12 -item WHODAS 2.0 in patients with KashinBeck disease. BMC Musculoskelet Disord. 2020; 21: 188. https://doi.org/10.1186/s12891-020-03210-8.

19. Schwalm A, Feng YS, Moock J, Kohlmann T. Differences in EQ-5D-3L health state valuations among patients with musculoskeletal diseases, health care professionals and healthy volunteers. Eur J Health Econ. 2015; 16: 865-77. https://doi.org/10.1007/s10198-014-0636-y.

20. Wang K, Yu J, Liu H, Liu Y, Liu N, Cao Y, et al. Endemic Kashin-Beck disease: A food-sourced osteoarthropathy. Semin Arthritis Rheum. 2020 ; 50: 366-72. https://doi.org/10.1016/j.semarthrit.2019.07.014.

\section{Tables}

Table 1 Demographic characteristics and clinical features of the patients 


\begin{tabular}{|c|c|c|c|}
\hline & $\begin{array}{l}\text { KBD patients } \\
(n=252)\end{array}$ & $\begin{array}{l}\text { Control group } \\
(n=260)\end{array}$ & $P$ \\
\hline Gender, n (\%) & & & 0.163 \\
\hline Male & 99 (39.29) & $118(45.38)$ & \\
\hline Female & $153(60.71)$ & $142(54.62)$ & \\
\hline Age (years) & $59.94 \pm 8.22$ & $59.10 \pm 8.60$ & $0.347^{\star}$ \\
\hline Age groups, years, n (\%) & & & 0.083 \\
\hline$<50$ & $21(8.33)$ & 33 (12.69) & \\
\hline $50 \sim 57$ & $76(30.16)$ & $68(26.15)$ & \\
\hline $58 \sim 64$ & $77(30.56)$ & $96(36.92)$ & \\
\hline$\geqq 65$ & 78 (30.95) & $63(24.23)$ & \\
\hline Height (m) & $1.55 \pm 0.09$ & $1.61 \pm 0.07$ & $<0.001^{*}$ \\
\hline \multicolumn{4}{|l|}{ Height groups (by sex, m) } \\
\hline Male & $1.61 \pm 0.07$ & $1.64 \pm 0.06$ & $<0.001$ \\
\hline Female & $1.51 \pm 0.09$ & $1.59 \pm 0.06$ & $<0.001^{*}$ \\
\hline Height groups, m, n (\%) & & & $<0.001$ \\
\hline$<1.50$ & $59(23.41)$ & $3(1.15)$ & \\
\hline $1.50 \sim 1.59$ & $104(41.27)$ & $105(40.38)$ & \\
\hline $1.60 \sim 1.69$ & 80 (31.75) & $121(46.54)$ & \\
\hline$\geqq 1.70$ & $9(3.57)$ & $31(11.92)$ & \\
\hline BMI $\left(\mathrm{kg} / \mathrm{m}^{2}\right)$ & $23.59 \pm 3.35$ & $23.17 \pm 2.99$ & $0.146^{\star}$ \\
\hline \multicolumn{4}{|l|}{ BMI groups (by sex, m) } \\
\hline Male & $22.83 \pm 3.14$ & $22.96 \pm 2.89$ & 0.794 \\
\hline Female & $24.06 \pm 3.41$ & $23.34 \pm 3.07$ & 0.059 \\
\hline BMI groups (kg/m²) & & & 0.086 \\
\hline$<18.5$ & $10(3.97)$ & $5(1.92)$ & \\
\hline $18.5 \llbracket 24.9$ & 161 (63.89) & $192(73.85)$ & \\
\hline $25.0 \rrbracket 29.9$ & $72(28.57)$ & $55(21.15)$ & \\
\hline$\geqq 30.0$ & $9(3.57)$ & $8(3.08)$ & \\
\hline Educational level, n (\%) & & & 0.507 \\
\hline No education completed & $87(34.52)$ & $75(28.85)$ & \\
\hline First level (primary school) & $76(30.16)$ & $95(36.54)$ & \\
\hline Secondary level (first phase) & $61(24.21)$ & $58(22.31)$ & \\
\hline Secondary level (second phase) & $26(10.32)$ & $29(11.15)$ & \\
\hline Third level (university and other higher education) & $2(0.79)$ & $3(1.15)$ & \\
\hline \multicolumn{4}{|l|}{ Grade of KBD, n (\%) } \\
\hline grade I & $24(9.52)$ & & \\
\hline grade II & $134(53.17)$ & & \\
\hline grade III & $94(37.30)$ & & \\
\hline Duration of symptoms (years) & $27.23 \pm 15.50$ & & \\
\hline Drinking, $\mathrm{n}(\%)$ & $31(12.30)$ & $42(16.15)$ & 0.213 \\
\hline Smoking, n (\%) & $56(22.22)$ & $61(23.46)$ & 0.738 \\
\hline Hypertension, n (\%) & $45(17.86)$ & $51(19.62)$ & 0.610 \\
\hline Diabetes mellitus, n (\%) & $20(7.94)$ & $23(8.85)$ & 0.711 \\
\hline
\end{tabular}


*The samples did not have homogeneity of variance and were compared by a nonparametric rank sum test as the "Kruskal-Wallis rank test".

Table 2 KBDQOL score comparison between KBD and control group

\begin{tabular}{|c|c|c|c|}
\hline \multirow[t]{2}{*}{ Abbreviated item content of KBDQOL } & \multicolumn{2}{|l|}{ Score } & \multirow[t]{2}{*}{$P^{\star}$} \\
\hline & KBD patients & Control group & \\
\hline Physical function & $2.43 \pm 0.75$ & $4.89 \pm 0.14$ & $<0.001$ \\
\hline Going up or down one step of stairs (Q1.1) & $2.57 \pm 1.24$ & $4.98 \pm 0.15$ & $<0.001$ \\
\hline Kneeling down (Q1.2) & $1.99 \pm 1.34$ & $4.97 \pm 0.16$ & $<0.001$ \\
\hline Bending down (Q1.3) & $3.30 \pm 1.49$ & $4.80 \pm 0.40$ & $<0.001$ \\
\hline Pain in joints (Q2.1) & $1.50 \pm 1.00$ & $5.00 \pm 0.00$ & $<0.001$ \\
\hline Duration of taking pain killer in days (Q2.2) & $2.85 \pm 1.67$ & $5.00 \pm 0.00$ & $<0.001$ \\
\hline Morning stiffness (Q2.3) & $1.51 \pm 1.20$ & $5.00 \pm 0.00$ & $<0.001$ \\
\hline Frequency of sleeplessness (Q3.4) & $3.29 \pm 1.50$ & $4.45 \pm 0.73$ & $<0.001$ \\
\hline Activity limitation & $3.60 \pm 0.89$ & $4.89 \pm 0.20$ & $<0.001$ \\
\hline Walking 1 km (Q1.4) & $2.83 \pm 1.44$ & $5.00 \pm 0.00$ & $<0.001$ \\
\hline Walking 100 m (Q1.5) & $4.27 \pm 1.11$ & $5.00 \pm 0.00$ & $<0.001$ \\
\hline Dressing yourself (Q1.6) & $4.38 \pm 0.97$ & $5.00 \pm 0.00$ & $<0.001$ \\
\hline Doing heavy labor such as farm work (Q1.7) & $2.19 \pm 1.42$ & $4.47 \pm 1.02$ & $<0.001$ \\
\hline Doing light labor such as cooking (Q1.8) & $4.32 \pm 1.10$ & $5.00 \pm 0.00$ & $<0.001$ \\
\hline Support of society & $3.23 \pm 0.85$ & $4.33 \pm 0.50$ & $<0.001$ \\
\hline Feel contribution to family duty (Q4.2) & $2.95 \pm 1.31$ & $4.91 \pm 0.53$ & $<0.001$ \\
\hline Feel supported by your family (Q5.5) & $3.92 \pm 1.22$ & $4.25 \pm 0.80$ & $<0.001$ \\
\hline Hang out, chat with neighbors (Q5.6) & $2.50 \pm 1.42$ & $3.94 \pm 1.15$ & $<0.001$ \\
\hline Have someone help you when you need (Q5.8) & $3.58 \pm 1.31$ & $4.24 \pm 0.77$ & $<0.001$ \\
\hline Economics & $2.49 \pm 0.92$ & $2.58 \pm 1.05$ & 0.511 \\
\hline Economy difficult (Q6.1) & $2.40 \pm 1.19$ & $2.65 \pm 1.20$ & 0.011 \\
\hline Borrow money (Q6.2) & $2.94 \pm 1.31$ & $3.06 \pm 1.24$ & 0.263 \\
\hline Can't afford treating disease (Q6.3) & $2.13 \pm 1.23$ & $2.02 \pm 1.17$ & 0.311 \\
\hline Mental health & $3.23 \pm 1.12$ & $4.33 \pm 0.38$ & $<0.001$ \\
\hline Feel happy (Q4.1) & $3.42 \pm 1.13$ & $3.78 \pm 0.91$ & $<0.001$ \\
\hline Feel yourself is a burden to others (Q4.4) & $3.24 \pm 3.35$ & $4.87 \pm 0.33$ & $<0.001$ \\
\hline Feel blue mood (Q4.5) & $3.13 \pm 1.32$ & $3.72 \pm 0.89$ & $<0.001$ \\
\hline Feel embarrassed about bodily appearance (Q4.6) & $2.73 \pm 1.56$ & $4.98 \pm 0.12$ & $<0.001$ \\
\hline Feel that no one take care of you (Q5.4) & $3.64 \pm 1.47$ & $4.27 \pm 0.77$ & $<0.001$ \\
\hline General health & $2.49 \pm 0.60$ & $3.73 \pm 0.31$ & $<0.001$ \\
\hline In general, how about your health? (Q7.1) & $2.20 \pm 0.86$ & $4.47 \pm 0.62$ & $<0.001$ \\
\hline Compared to the same age and gender people, how about your health? (Q7.2) & $1.74 \pm 0.78$ & $2.97 \pm 0.25$ & $<0.001$ \\
\hline Compared to 1 month ago, how about your health? (Q7.3) & $2.79 \pm 0.59$ & $3.00 \pm 0.16$ & $<0.001$ \\
\hline In general, how satisfied are you with your quality of life (Q7.4) & $3.24 \pm 1.12$ & $4.47 \pm 0.62$ & $<0.001$ \\
\hline
\end{tabular}

*The samples did not have homogeneity of variance and were compared by a nonparametric rank sum test as the "Kruskal-Wallis rank test".

Table 3 The monofactor analysis of the KBDQOL scores in patients with KBD 


\begin{tabular}{|c|c|c|c|c|c|c|c|c|c|c|c|c|}
\hline \multirow[t]{2}{*}{ Variable } & \multicolumn{2}{|c|}{ Physical function } & \multicolumn{2}{|c|}{ Activity limitation } & \multicolumn{2}{|c|}{ Support of society } & \multicolumn{2}{|l|}{ Economics } & \multicolumn{2}{|c|}{ Mental health } & \multicolumn{2}{|c|}{ General health } \\
\hline & Score & $P$ & Score & $P$ & Score & $P$ & Score & $P$ & Score & $P$ & Score & $P$ \\
\hline Sex & & 0.706 & & 0.886 & & 0.548 & & 0.894 & & 0.405 & & 0.134 \\
\hline Male & $2.43 \pm 0.65$ & & $3.60 \pm 0.87$ & & $3.21 \pm 0.90$ & & $2.48 \pm 0.90$ & & $3.35 \pm 1.45$ & & $2.54 \pm 0.61$ & \\
\hline Female & $2.43 \pm 0.82$ & & $3.59 \pm 0.91$ & & $3.24 \pm 0.82$ & & $2.50 \pm 0.94$ & & $3.15 \pm 0.85$ & & $2.45 \pm 0.58$ & \\
\hline Age (years) & & 0.001 & & $<0.001 \#$ & & 0.229 & & 0.961 & & 0.010 & & 0.007 \\
\hline$<50$ & $2.26 \pm 0.86$ & & $3.63 \pm 0.95$ & & $3.18 \pm 0.90$ & & $2.46 \pm 1.08$ & & $3.01 \pm 0.74$ & & $2.11 \pm 0.78$ & \\
\hline $50 \sim 57$ & $2.68 \pm 0.72$ & & $3.99 \pm 0.79$ & & $3.38 \pm 0.95$ & & $2.45 \pm 0.79$ & & $3.36 \pm 0.92$ & & $2.48 \pm 0.53$ & \\
\hline $58 \sim 64$ & $2.41 \pm 0.78$ & & $3.55 \pm 0.84$ & & $3.21 \pm 0.79$ & & $2.48 \pm 1.03$ & & $2.96 \pm 0.83$ & & $2.43 \pm 0.56$ & \\
\hline$\geqq 65$ & $2.25 \pm 0.69$ & & $3.25 \pm 0.88$ & & $3.12 \pm 0.79$ & & $2.55 \pm 0.89$ & & $3.43 \pm 1.53$ & & $2.65 \pm 0.59$ & \\
\hline Height (m) & & 0.007 & & 0.002 & & 0.348 & & 0.430 & & 0.533 & & 0.004 \\
\hline$<1.50$ & $2.16 \pm 0.65$ & & $3.31 \pm 0.94$ & & $3.05 \pm 0.72$ & & $2.34 \pm 0.89$ & & $3.07 \pm 0.76$ & & $2.29 \pm 0.59$ & \\
\hline $1.50 \sim 1.59$ & $2.53 \pm 0.80$ & & $3.59 \pm 0.89$ & & $3.27 \pm 0.89$ & & $2.56 \pm 0.85$ & & $3.33 \pm 1.40$ & & $2.48 \pm 0.61$ & \\
\hline $1.60 \sim 1.69$ & $2.46 \pm 0.75$ & & $3.72 \pm 0.81$ & & $3.28 \pm 0.85$ & & $2.51 \pm 0.99$ & & $3.25 \pm 0.96$ & & $2.6 \pm 0.57$ & \\
\hline$\geqq 1.70$ & $2.79 \pm 0.46$ & & $4.44 \pm 0.53$ & & $3.50 \pm 1.09$ & & $2.56 \pm 1.26$ & & $3.02 \pm 0.87$ & & $2.86 \pm 0.33$ & \\
\hline $\begin{array}{l}\text { Weight status } \\
\text { (by BMl, kg/m²) }\end{array}$ & & 0.251 & & 0.048 & & 0.811 & & 0.934 & & 0.419 & & 0.009 \\
\hline$<18.5$ & $2.13 \pm 0.44$ & & $3.40 \pm 0.85$ & & $3.13 \pm 0.85$ & & $2.60 \pm 0.58$ & & $3.28 \pm 1.06$ & & $2.50 \pm 0.62$ & \\
\hline $18.5 \varangle 24.9$ & $2.46 \pm 0.75$ & & $3.65 \pm 0.83$ & & $3.25 \pm 0.82$ & & $2.48 \pm 0.92$ & & $3.23 \pm 1.24$ & & $2.53 \pm 0.54$ & \\
\hline $25.0 \varangle 29.9$ & $2.44 \pm 0.80$ & & $3.61 \pm 1.00$ & & $3.25 \pm 0.89$ & & $2.50 \pm 0.99$ & & $3.28 \pm 0.91$ & & $2.48 \pm 0.68$ & \\
\hline$\geqq 30.0$ & $2.03 \pm 0.67$ & & $2.82 \pm 0.74$ & & $2.86 \pm 1.08$ & & $2.44 \pm 0.85$ & & $2.82 \pm 0.49$ & & $1.78 \pm 0.48$ & \\
\hline Education & & 0.001 & & 0.001 & & 0.004 & & 0.431 & & 0.142 & & 0.181 \\
\hline $\begin{array}{l}\text { No education } \\
\text { completed }\end{array}$ & $2.18 \pm 0.66$ & & $3.31 \pm 0.89$ & & $3.08 \pm 0.74$ & & $2.42 \pm 0.91$ & & $3.07 \pm 0.81$ & & $2.42 \pm 0.59$ & \\
\hline First level & $2.45 \pm 0.76$ & & $3.58 \pm 0.90$ & & $3.09 \pm 0.85$ & & $2.43 \pm 0.79$ & & $3.28 \pm 1.56$ & & $2.42 \pm 0.67$ & \\
\hline $\begin{array}{l}\text { Secondary level } \\
\text { (first phase) }\end{array}$ & $2.66 \pm 0.84$ & & $3.83 \pm 0.83$ & & $3.49 \pm 0.90$ & & $2.60 \pm 0.99$ & & $3.27 \pm 0.95$ & & $2.60 \pm 0.52$ & \\
\hline $\begin{array}{l}\text { Secondary level } \\
\text { (second phase) }\end{array}$ & $2.57 \pm 0.57$ & & $3.98 \pm 0.73$ & & $3.40 \pm 0.82$ & & $2.62 \pm 1.04$ & & $3.45 \pm 0.88$ & & $2.61 \pm 0.49$ & \\
\hline Third level & $3.36 \pm 0.71$ & & $4.50 \pm 0.42$ & & $5.00 \pm 0.00$ & & $3.67 \pm 1.89$ & & $4.30 \pm 0.42$ & & $3.13 \pm 0.88$ & \\
\hline Grade of KBD & & 0.031 & & 0.007 & & 0.567 & & 0.014 & & 0.507 & & $<0.00$ \\
\hline Grade I & $2.48 \pm 0.84$ & & $3.63 \pm 0.85$ & & $3.28 \pm 0.79$ & & $2.90 \pm 0.88$ & & $3.23 \pm 0.73$ & & $2.54 \pm 0.50$ & \\
\hline Grade II & $2.53 \pm 0.75$ & & $3.76 \pm 0.86$ & & $3.29 \pm 0.85$ & & $2.54 \pm 0.98$ & & $3.24 \pm 0.85$ & & $2.67 \pm 0.48$ & \\
\hline Grade III & $2.26 \pm 0.72$ & & $3.35 \pm 0.89$ & & $3.14 \pm 0.87$ & & $2.32 \pm 0.81$ & & $3.21 \pm 1.50$ & & $2.22 \pm 0.67$ & \\
\hline $\begin{array}{l}\text { Duration of } \\
\text { symptoms (years) }\end{array}$ & & 0.777 & & 0.522 & & 0.799 & & 0.667 & & 0.136 & & 0.332 \\
\hline$<10$ & $2.55 \pm 0.91$ & & $3.43 \pm 0.92$ & & $3.18 \pm 0.78$ & & $2.35 \pm 1.00$ & & $3.26 \pm 0.82$ & & $2.60 \pm 0.51$ & \\
\hline $10 \sim 29$ & $2.45 \pm 0.71$ & & $3.67 \pm 0.84$ & & $3.27 \pm 0.84$ & & $2.57 \pm 0.93$ & & $3.31 \pm 1.43$ & & $2.50 \pm 0.60$ & \\
\hline $30 \sim 44$ & $2.37 \pm 0.73$ & & $3.60 \pm 0.88$ & & $3.17 \pm 0.87$ & & $2.47 \pm 0.90$ & & $3.04 \pm 0.84$ & & $2.39 \pm 0.60$ & \\
\hline$\geqq 45$ & $2.39 \pm 0.80$ & & $3.53 \pm 1.01$ & & $3.32 \pm 0.90$ & & $2.47 \pm 0.90$ & & $3.45 \pm 1.00$ & & $2.57 \pm 0.64$ & \\
\hline Drinking & & 0.149 & & 0.132 & & 0.311 & & 0.995 & & 0.785 & & 0.141 \\
\hline Absent & $2.41 \pm 0.78$ & & $3.56 \pm 0.90$ & & $3.21 \pm 0.84$ & & $2.49 \pm 0.92$ & & $3.24 \pm 1.14$ & & $2.46 \pm 0.59$ & \\
\hline Present & $2.55 \pm 0.56$ & & $3.86 \pm 0.76$ & & $3.39 \pm 0.93$ & & $2.52 \pm 0.97$ & & $3.18 \pm 1.00$ & & $2.64 \pm 0.60$ & \\
\hline Smoking & & 0.829 & & 0.437 & & 0.605 & & 0.902 & & 0.796 & & 0.604 \\
\hline Absent & $2.44 \pm 0.78$ & & $3.57 \pm 0.90$ & & $3.24 \pm 0.86$ & & $2.51 \pm 0.95$ & & $3.20 \pm 0.88$ & & $2.48 \pm 0.60$ & \\
\hline
\end{tabular}




\begin{tabular}{|c|c|c|c|c|c|c|c|c|c|c|c|c|}
\hline Present & $2.39 \pm 0.67$ & & $3.68 \pm 0.85$ & & $3.20 \pm 0.81$ & & $2.42 \pm 0.81$ & & $3.34 \pm 1.73$ & & $2.50 \pm 0.59$ & \\
\hline Blood presure & & 0.646 & & 0.601 & & 0.199 & & 0.530 & & 0.472 & & 0.154 \\
\hline Normotension & $2.44 \pm 0.76$ & & $3.59 \pm 0.90$ & & $3.25 \pm 0.84$ & & $2.51 \pm 0.92$ & & $3.21 \pm 0.91$ & & $2.51 \pm 0.59$ & \\
\hline Hypertension & $2.38 \pm 0.74$ & & $3.64 \pm 0.88$ & & $3.13 \pm 0.90$ & & $2.42 \pm 0.94$ & & $3.31 \pm 1.84$ & & $2.36 \pm 0.60$ & \\
\hline Blood sugar & & 0.717 & & 0.486 & & 0.949 & & 0.220 & & 0.633 & & 0.396 \\
\hline Diabetes mellitus & $2.43 \pm 0.75$ & & $3.60 \pm 0.90$ & & $3.23 \pm 0.84$ & & $2.52 \pm 0.92$ & & $3.23 \pm 1.14$ & & $2.48 \pm 0.60$ & \\
\hline $\begin{array}{l}\text { Normal blood } \\
\text { sugar }\end{array}$ & $2.44 \pm 0.84$ & & $3.52 \pm 0.74$ & & $3.29 \pm 0.95$ & & $2.22 \pm 0.85$ & & $3.22 \pm 1.00$ & & $2.6 \pm 0.50$ & \\
\hline
\end{tabular}

$P$, the samples did not have homogeneity of variance and were compared by a nonparametric rank sum test as the "Kruskal-Wallis rank test"except labeled “*”.

*Mann-Whitney U test.

\#The samples had homogeneity of variance and normal distribution were compared by a one-way ANOVA.

Table 4 Multivariate analysis for control of confounding variables 


\begin{tabular}{|c|c|c|c|c|c|c|c|c|c|c|c|c|}
\hline \multirow[t]{2}{*}{ Variable } & \multicolumn{2}{|c|}{$\begin{array}{l}\text { Physical } \\
\text { function }\end{array}$} & \multicolumn{2}{|c|}{ Activity limitation } & \multicolumn{2}{|c|}{ Support of society } & \multicolumn{2}{|c|}{ Economics } & \multicolumn{2}{|c|}{ Mental health } & \multicolumn{2}{|c|}{ General health } \\
\hline & $P$ & $\operatorname{Exp}(B)$ & $P$ & $\operatorname{Exp}(B)$ & $P$ & $\operatorname{Exp}(B)$ & $P$ & $\operatorname{Exp}(B)$ & $P$ & $\operatorname{Exp}(B)$ & $P$ & $\operatorname{Exp}(B)$ \\
\hline \multicolumn{13}{|l|}{ Sex } \\
\hline Male & 0.130 & 0.555 & $<0.001$ & 0.225 & 0.631 & 0.836 & 0.760 & 0.893 & 0.094 & 1.867 & 0.792 & 0.898 \\
\hline Female & & 1 & & 1 & & 1 & & & & 1 & & 1 \\
\hline Age & 0.363 & 0.992 & $<0.001$ & 0.973 & 0.493 & 0.989 & 0.114 & 1.026 & 0.520 & 1.010 & 0.007 & 1.049 \\
\hline Height & 0.489 & 3.001 & 0.038 & 27.294 & 0.903 & 0.831 & 0.629 & 0.481 & 0.386 & 0.269 & 0.120 & 13.987 \\
\hline Weight status (by BMI) & 0.172 & 0.948 & 0.088 & 0.936 & 0.550 & 0.978 & 0.980 & 1.001 & 0.989 & 0.999 & 0.940 & 0.868 \\
\hline \multicolumn{13}{|l|}{ Education } \\
\hline No education completed & 0.385 & 0.279 & 0.999 & $\begin{array}{l}2.423 \mathrm{E}- \\
10\end{array}$ & 0.999 & $\begin{array}{l}2.023 \mathrm{E}- \\
10\end{array}$ & 0.086 & 0.085 & 0.999 & $\begin{array}{l}2.551 \mathrm{E}- \\
10\end{array}$ & 0.122 & 0.092 \\
\hline First level & 0.675 & 0.545 & 0.999 & $\begin{array}{l}3.764 \mathrm{E}- \\
10\end{array}$ & 0.999 & $\begin{array}{l}2.628 \mathrm{E}- \\
10\end{array}$ & 0.123 & 0.113 & 0.999 & $\begin{array}{l}3.033 \mathrm{E}- \\
10\end{array}$ & 0.150 & 0.112 \\
\hline Secondary level (first phase) & 0.821 & 0.721 & 0.999 & $\begin{array}{l}6.012 \mathrm{E}- \\
10\end{array}$ & 0.999 & $\begin{array}{l}5.300 \mathrm{E}- \\
10\end{array}$ & 0.204 & 0.166 & 0.999 & $\begin{array}{l}3.723 \mathrm{E}- \\
10\end{array}$ & 0.189 & 0.136 \\
\hline $\begin{array}{l}\text { Secondary level (second } \\
\text { phase) }\end{array}$ & 0.847 & 0.754 & 0.999 & $\begin{array}{l}6.826 \mathrm{E}- \\
10\end{array}$ & 0.999 & $\begin{array}{l}4.079 \mathrm{E}- \\
10\end{array}$ & 0.215 & 0.171 & 0.999 & $\begin{array}{l}4.931 \mathrm{E}- \\
10\end{array}$ & 0.182 & 0.129 \\
\hline Third level & & 1 & & 1 & & 1 & & 1 & & 1 & & 1 \\
\hline \multicolumn{13}{|l|}{ Grade of KBD } \\
\hline Grade I & 0.805 & 1.117 & 0.591 & 1.275 & 0.817 & 1.106 & 0.005 & 3.413 & 0.439 & 1.400 & 0.005 & 3.997 \\
\hline Grade II & 0.007 & 2.067 & 0.001 & 2.502 & 0.473 & 1.203 & 0.179 & 1.410 & 0.322 & 1.282 & $<0.001$ & 5.635 \\
\hline Grade III & & 1 & & 1 & & 1 & & 1 & & 1 & & 1 \\
\hline Duration of symptoms & 0.239 & 0.990 & 0.023 & 1.020 & 0.811 & 1.002 & 0.498 & 0.995 & 0.196 & 0.990 & 0.180 & 0.988 \\
\hline \multicolumn{13}{|l|}{ Drinking } \\
\hline Absent & 0.692 & 0.845 & 0.069 & 0.398 & 0.572 & 0.790 & 0.557 & 1.272 & 0.371 & 1.448 & 0.360 & 0.663 \\
\hline Present & & 1 & & 1 & & 1 & & 1 & & 1 & & 1 \\
\hline \multicolumn{13}{|l|}{ Smoking } \\
\hline Absent & 0.395 & 1.405 & 0.147 & 0.560 & 0.825 & 1.089 & 0.957 & 1.021 & 0.141 & 1.758 & 0.301 & 1.547 \\
\hline Present & & 1 & & 1 & & 1 & & 1 & & 1 & & \\
\hline \multicolumn{13}{|l|}{ Blood presure } \\
\hline Normotension & 0.849 & 1.063 & 0.626 & 0.854 & 0.377 & 1.312 & 0.655 & 1.146 & 0.588 & 1.180 & 0.112 & 1.716 \\
\hline Hypertension & & 1 & & 1 & & 1 & & 1 & & 1 & & 1 \\
\hline \multicolumn{13}{|l|}{ Blood sugar } \\
\hline Diabetes mellitus & 0.797 & 1.127 & 0.942 & 1.035 & 0.778 & 1.134 & 0.213 & 1.743 & 0.869 & 1.076 & 0.734 & 0.849 \\
\hline Normal blood sugar & & 1 & & 1 & & 1 & & 1 & & 1 & & 1 \\
\hline
\end{tabular}

\section{Figures}




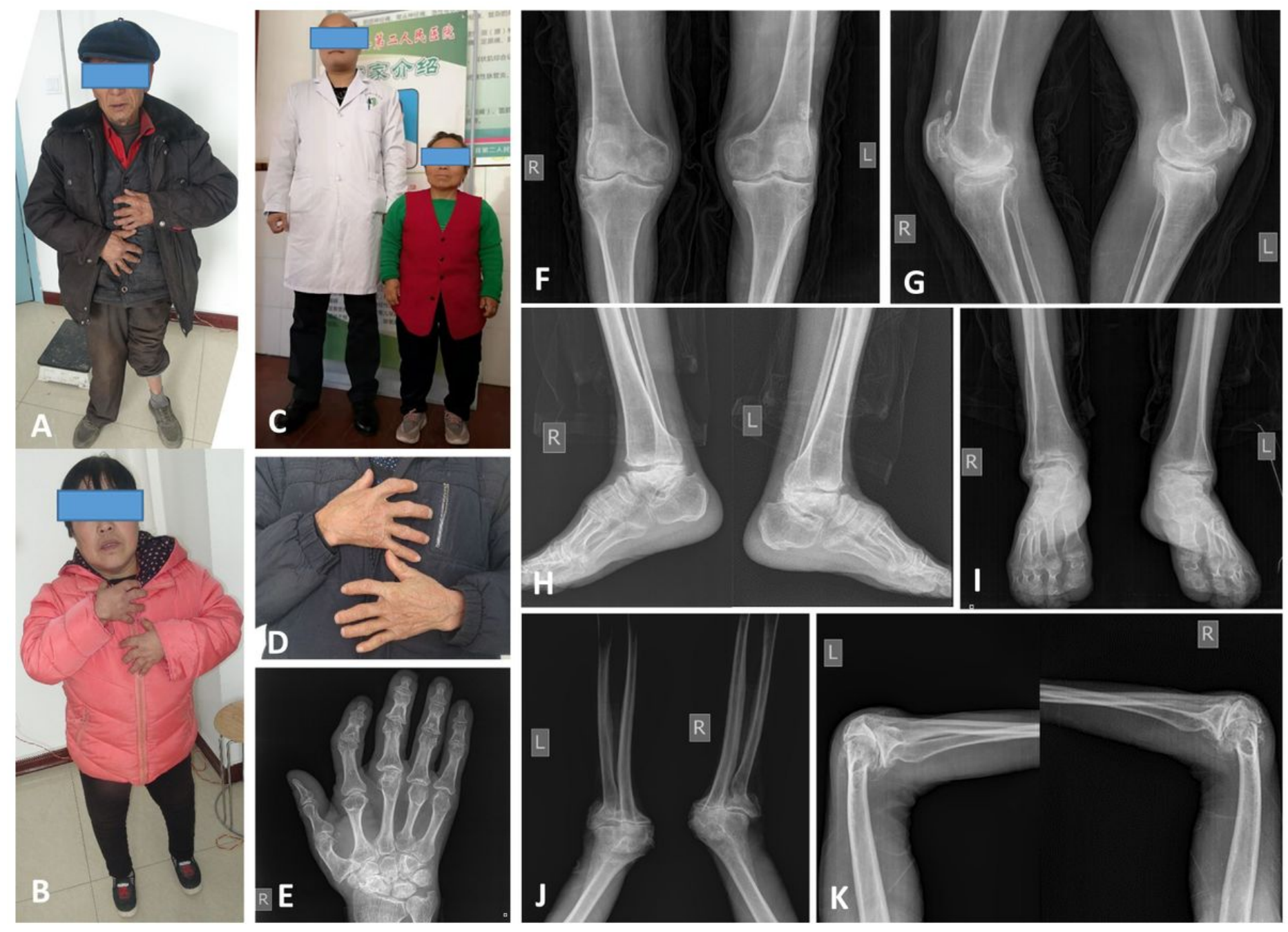

\section{Figure 1}

The physical characteristics and joint X-ray features of KBD patients

The typical characteristics of adult KBD patients are severe short stature $(A, B, C)$, short finger deformity $(A, B, C)$, severe deformity and osteophyte formation in the finger joints $(A, B, C, D, E)$, knee joints $(F, G)$, ankle joints $(H, I)$, and elbow joints $(J, K)$. The clinical symptoms mainly include joint pain and restricted mobility, which seriously affect the life and work of the patient. 

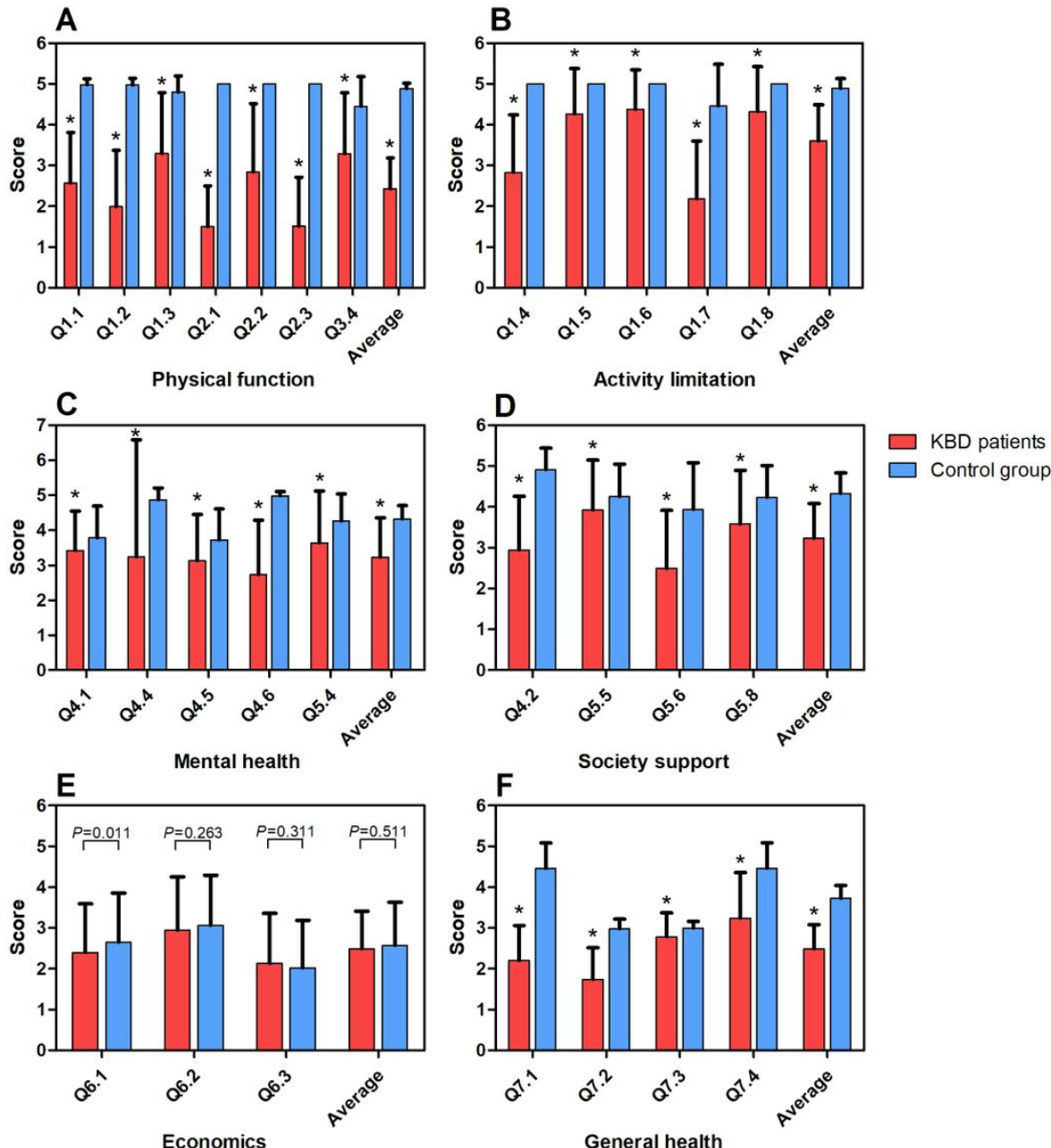

Figure 2

\section{Comparison of KBDQOL scores between KBD and control group}

KBD patients on the KBDQOL questionnaire had an average score of physical function(A), activity limitation (B), mental health (C), support of society(D) and general health $(F)$, which was significantly lower than the average score of the control group. The average score of KBD patients in economics (E), which was not statistically different from the control group, but on the average score of Q6.1 question (E), KBD patients were significantly lower than the control group.

\section{Supplementary Files}

This is a list of supplementary files associated with this preprint. Click to download.

- SupplementaryTable1.docx 